\title{
Neurovascular Compression: Sympathetic Activity in Severe Arterial Hypertension
}

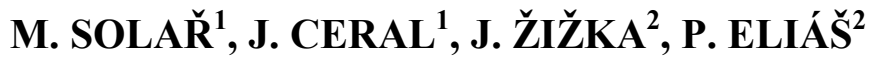 \\ Departments of Internal Medicine ${ }^{1}$ and Radiology ${ }^{2}$, Charles University Prague, Medical Faculty \\ Hradec Králové, University Hospital, Hradec Králové, Czech Republic
}

Received November 20, 2008

Accepted December 8, 2008

On-line December 17, 2008

\begin{abstract}
Summary
Compression of the rostral ventrolateral medulla oblongata (RVLM) by an abnormally located artery is regarded as one possible cause of arterial hypertension. There exists a limited set of data suggesting that increased sympathetic activity in patients with RVLM compression may lead to arterial hypertension. Accordingly, we decided to assess the sympathetic activity in patients with severe arterial hypertension and to investigate any correlation with the presence of RVLM compression. Sixty-four patients with severe arterial hypertension were enrolled in our study. Sympathetic activity was evaluated using 24-hour urinary norepinephrine as measured by high-pressure liquid chromatography with electrochemical detection. The presence of RVLM compression was assessed with magnetic resonance imaging. Neurovascular compression of the RVLM was identified in 40 patients, 27 of whom presented left-sided compression. Twenty-four hour urinary norepinephrine averaged $263.6 \pm 135.9 \mathrm{nmol}$ in patients with neurovascular compression $255.6 \pm 137.3 \mathrm{nmol}$ in those with left-sided compression and $251.6 \pm 138.5 \mathrm{nmol}$ in patients without RVLM compression. We did not identify any increase in urinary norepinephrine in patients with severe arterial hypertension and neurovascular compression of the RVLM. Our results do not support the hypothesis that neurovascular compression of RVLM may exhibit a sympathetically mediated increase in blood pressure.
\end{abstract}

\section{Key words}

Neurovascular compression - Arterial hypertension - Magnetic resonance imaging

\section{Corresponding author}

J. Ceral, Department of Internal Medicine, University Hospital Hradec Králové, Sokolská 581, 50005 Hradec Králové, Czech Republic. Fax: +420495832006. E-mail: ceral@seznam.cz
Rostral ventrolateral medulla (RVLM) is a brainstem center that is located below the retroolivary sulcus, anterior to the fibres of the glossopharyngeal and vagal nerves. The adrenergic neurons of the RVLM play a role in the control of blood pressure. It has been hypothesized that RVLM compression by an anomalous artery may be a cause of arterial hypertension in humans (Jannetta et al. 1985). However, systematic evaluations of brainstem morphology with magnetic resonance imaging (MRI) found no difference in the incidence of RVLM compression between hypertensive and normotensive subjects (Hohenbleicher et al. 2001, Thuerl et al. 2001, Žižka et al. 2004).

In contrast, the concept of neurogenic hypertension is supported by several reports. Increased plasma norepinephrine levels were observed in patients with arterial hypertension and neurovascular compression (Morimoto et al. 1999a). Moreover, neurosurgical decompression was associated with the decrease of both blood pressure (Geiger et al. 1998) and urinary norepinephrine concentration (Morimoto et al. 1999b).

The main limitation of morphological studies is the inability to assess the functional impact of vascular compressions on the RVLM. Therefore, we decided to assess sympathetic activity in patients with severe arterial hypertension, and to correlate these observations with the presence or absence of RVLM vascular compression.

All patients with arterial hypertension treated in our hypertension clinic were screened for the purpose of this study. The study included those individuals with arterial hypertension lasting for more than two years, who 
had documented systolic blood pressure $\geq 180 \mathrm{~mm} \mathrm{Hg}$ and/or diastolic blood pressure $\geq 110 \mathrm{~mm} \mathrm{Hg}$ and who were undergoing treatment with a combination of three or more antihypertensive drugs. The patients with a secondary form of arterial hypertension and/or a contraindication to MRI were excluded.

Based on these criteria, 64 patients (30 females) were enrolled. The study protocol evaluated sympathetic activity and aimed to identify any correlations with the presence or absence of RVLM compression. Antihypertensive medication was not discontinued; this decision was justified by ethical considerations. The study was approved by the institutional review board and informed consent was obtained from all subjects.

The activity of the sympathetic nervous system was assessed using 24-h urinary secretion of norepinephrine. Urinary norepinephrine was measured by high pressure liquid chromatography with electrochemical detection.

The presence of RVLM compression was evaluated with MRI; MRI examinations were performed on a 1.0 Tesla system (Magnetom Expert; Siemens, Erlangen, Germany). The imaging technique and the method of the assessment of RVLM vascular compression is described in detail elsewhere (Žižka et al. 2004). Briefly, RVLM compression was defined as either contact of the artery with the brainstem or pressure from the artery leading to apparent deformity of the brainstem contour. The patients with neurovascular contact and with pressure-induced deformation were evaluated separately.
Since it is unclear whether only the left side (Jannetta et al. 1985) or both sides of the RVLM may be involved in the development of arterial hypertension, all patients were evaluated both for the presence of any RVLM compression and for compression of the left RVLM.

Statistical analysis of the acquired data was performed by parametric tests using the Medcalc $\AA$ version 9 software package.

Vascular compression of the RVLM was idenfitied in 40 patients $(62.5 \%)$, of which 27 (67.5\%) exhibited compression on the left side. The neurovascular compression was described as contact-related in 34 patients and as pressure-induced brainstem deformation in further six individuals. All of the latter cases were left-sided. We found no vascular compression of the RVLM in 24 patients $(37.5 \%)$ and these individuals served as the control group. Patients with and without RVLM compression did not differ with regard to age, body mass index or the number of antihypertensive drugs used (Table 1).

No difference in 24-h norepinephrine excretion was found between the group without RVLM compression and the patients who exhibited any or leftsided RVLM compression (Table 1).

No differences were observed when comparing those patients who exhibited pressure-induced brainstem deformation with both patients suffering from neurovascular contact-related RVLM compression and controls without any compression.

Table 1. Evaluation of sympathetic activity in patients with severe arterial hypertension, with and without neurovascular compression.

\begin{tabular}{|c|c|c|c|c|}
\hline & $\begin{array}{c}\text { Any RVLM } \\
\text { compression } \\
\text { (contacts + } \\
\text { pressure- } \\
\text { induced } \\
\text { deformations) }\end{array}$ & $\begin{array}{c}\text { Left RVLM } \\
\text { compression } \\
\text { (contacts + } \\
\text { pressure- } \\
\text { induced } \\
\text { deformations) }\end{array}$ & $\begin{array}{c}\text { RVLM } \\
\text { pressure- } \\
\text { induced } \\
\text { deformation }\end{array}$ & $\begin{array}{c}\text { No RVLM } \\
\text { compression }\end{array}$ \\
\hline Number of patients & 40 & 27 & 6 & 24 \\
\hline Age (years) & $54 \pm 11$ & $55 \pm 11$ & $62 \pm 10$ & $50 \pm 12$ \\
\hline$B M I\left(\mathrm{~kg} / \mathrm{m}^{2}\right)$ & $28.6 \pm 4.5$ & $28.5 \pm 3.4$ & $27.5 \pm 1.2$ & $29.5 \pm 3.9$ \\
\hline Number of antihypertensive drugs & $4.2 \pm 1.2$ & $3.9 \pm 0.9$ & $3.7 \pm 0.5$ & $4.1 \pm 1.1$ \\
\hline Urinary norepinephrine (nmol/24 h) & $263.6 \pm 135.9$ & $255.6 \pm 137.3$ & $200.7 \pm 82.9$ & $251.6 \pm 138.5$ \\
\hline
\end{tabular}

Table 1 describes the principal group characteristics and 24-h urinary norepinephrine excretion in patients with and without RVLM compression. Values are expressed as means \pm S.D.. We observed no statistically significant difference in any parameter evaluated between the study groups. BMI, body mass index; RVLM, rostral ventrolateral medulla. 
As the morphological studies failed to confirm the hypothesis regarding the neurovascular origin of arterial hypertension, we searched for other parameters to identify those patients for whom blood pressure elevation may result from neurovascular compression. Our study enrolled only those patients with established severe arterial hypertension and without any evidence of secondary causes. The logic behind this selection was that - if the results of our study had been positive - candidates for neurosurgical decompression would be selected mainly from this cohort.

Although there is no method that is universally recommended for the assessment of central sympathetic activity, we are aware of the limitations regarding our choice of the diagnostic method of urinary norepinephrine excretion (Grassi and Esler 1999). However, other researchers have observed increased plasma norepinephrine levels (Morimoto et al. 1999a) and the decrease of urinary norepinephrine after neurosurgical decompression (Morimoto et al. 1999b) in patients with neurovascular compression and arterial hypertension.

Several reports have used sophisticated methods to measure central sympathetic outflow. A number of authors have used such approaches to describe increased sympathetic activity in hypertensive patients with RVLM compression (Schobel et al. 2002, Smith et al. 2004, Sendeski et al. 2006). However, the numbers of patients enrolled in individual studies have been rather small, and researchers have been unable to identify any discriminative value that may associate elevated sympathetic activity with neurovascular compression and arterial hypertension. Moreover, there exists little uniformity among the reports in respect to MRI techniques, the definitions of neurovascular compression and the anatomic extent of the RVLM. Not all the studies differentiate the neurovascular compressions into contactbased phenomena and pressure-induced deformations when the artery is indented into the surface of the medulla. Sendeski et al. (2006) reported increased sympathetic activity only in the latter group. However, the number of patients for whom this held true was low in the aforementioned study. Our study also included a relatively small number of these subjects.

The blood pressure-lowering effect of surgical decompression is another argument that is often used to support the existence of neurogenic hypertension. However, data from neurosurgical interventions should be treated with caution. First, there exist no controlled randomized studies. Second, the number of operations performed to date is rather low and a lowering of blood pressure was not observed in all patients (Frank et al. 2001). A postoperative blood pressure reduction may be explained not only by neurovascular decompression itself but also as a non-specific functional effect of neurosurgical intervention on the brainstem centers. A recent report by Frank et al. (2008) suggested only a transient effect of neurosurgical decompression on blood pressure and sympathetic control.

In conclusion, we think that currently available data do not support the role of neurovascular compression as a definite causal factor in arterial hypertension. We did not identify increased sympathetic activity in patients with severe arterial hypertension and neurovascular compression of the RVLM.

\section{Conflict of Interest}

There is no conflict of interest.

\section{Acknowledgements}

Our work was supported by research projects MSM0021620817 and MZO 00179906.

\section{References}

FRANK H, SCHOBEL HP, HEUSSER K, GEIGER H, FAHLBUSCH R, NARAGHI R: Long-term results after microvascular decompression in essential hypertension. Stroke 32: 2950-2955, 2001.

FRANK H, HEUSSER K, GEIGER H, FAHLBUSCH R, NARAGHI R, SCHOBEL HP: Temporary reduction of blood pressure and sympathetic nerve activity in hypertensive patients after microvascular decompression. Stroke $\mathbf{4 0}$ : 47-51, 2009.

GEIGER H, NARAGHI R, SCHOBEL HP, FRANK H, STERZEL RB, FAHLBUSCH R: Decrease of blood pressure by ventrolateral medullary decompression in essential hypertension. Lancet 352: 446-449, 1998.

GRASSI G, ESLER M: How to assess sympathetic activity in humans. $J$ Hypertens 17: 719-734, 1999. 
HOHENBLEICHER H, SCMITZ SA, KOENNECKE HC, OFFERMANN R, OFFERMANN J, ZEYTOUNTCHAIN H, WOLF KJ, DISTLER A, SHARMA AM: Neurovascular contact of cranial nerve IX and X root-entry zone in hypertensive patients. Hypertension 37: 176-181, 2001.

JANNETTA PJ, SEGAL R, WOLFSON SK JR, DUJOVNY M, SEMBA A, COOK EE: Neurogenic hypertension: etiology and surgical treatment. II. Observations in an experimental nonhuman primate model. Ann Surg 202: 253-261, 1985.

MORIMOTO S, SASAKI S, ITOH H, NAKATA T, TAKEDA K, NAKAGAWA M, FURUYA S, NARUSE S, FUKUYAMA R, FUSHIKI S: Sympathetic activation and contribution of genetic factors in hypertension with neurovascular compression of the rostral ventrolateral medulla. J Hypertens 17: 1577-1582, 1999a.

MORIMOTO S, SASAKI S, TAKEDA K, FURUYA S, NARUSE S, MATSUMOTO K, HIGUCHI T, SAITO M, NAKAGAWA M: Decreases in blood pressure and sympathetic nerve activity by microvascular decompression of the rostral ventrolateral medulla in essential hypertension. Stroke 30: 1707-1710, 1999b.

SCHOBEL HB, FRANK H, NARAGHI R, GEIGER H, TITZ E, HEUSSER K: Hypertension in patients with neurovascular compression is associated with increased central sympathetic outflow. $J$ Am Soc Nephrol 13: $35-41,2002$.

SENDESKI MM, CONSOLIM-COLOMBO FM, LEITE CC, RUBIRA MC, LESSA P, KRIEGER EM: Increased sympathetic nerve activity correlates with neurovascular compression at the rostral ventrolateral medulla. Hypertension 47: 988-995, 2006.

SMITH PA, MEANEY JF, GRAHAM LN, STOKER JB, MACKINTOSH AF, MARY DA, BALL SG: Relationship of neurovascular compression to central sympathetic discharge and essential hypertension. $J$ Am Coll Cardiol 43: 1453-1458, 2004.

THUERL C, RUMP LC, OTTO M, WINTERER JT, SCHNEIDER B, FUNK L, LAUBENBERGER J: Neurovascular contact of the brain stem in hypertensive and normotensive subjects: MR findings and clinical significance. Am J Neuroradiol 22: 476-480, 2001.

ŽIŽKA J, CERAL J, ELIÁŠ P, TINTĚRA J, KLZO L, SOLAŘ M, STRAKA L: Vascular compression of rostral medulla oblongata: prospective MR imaging study in hypertensive and normotensive subjects. Radiology 230: 65-69, 2004. 